\title{
Uterine Endometrial Regeneration and Conception Rate Following Oestrus Induction with CIDR and Ovsynch Treatment in Postpartum Dairy Cows
}

\author{
C. Velladurai", S. Alagar", M. Selvaraju and R. Ezakial Napolean \\ Department of Veterinary Gynaecology and Obstetrics, Veterinary College and Research \\ Institute, Namakkal-2, Tamil Nadu, India \\ *Corresponding author
}

\section{A B S T R A C T}

Endometrial histopathology was studied in 16 postpartum dairy cows. Endometrial biopsy was taken from the all experimental animals, to study the histopathological changes of the uterine endometrium. 8 cows in group $\mathrm{I}(\mathrm{n}=8)$ on day 2 postpartum and were treated with

\section{Keywords}

Uterine

endometrium,

Conception rate,

CIDR, Ovsynch,

Cows, Postpartum

Article Info

Accepted:

10 February 2018

Available Online:

10 March 2018 an intramuscular injection of $5 \mathrm{mg}$ methyl ergometrine maleate. All the cows in group I were inserted with Controlled Internal Drug Release device (CIDR) on day 45-55 postpartum intra-vaginally. Whereas 8 cows in group II $(n=8)$ were selected at day 35-50 postpartum and supplemented with TANUVAS mineral mixture and treated with ovsynch treatment. In group I cows on day 10 postpartum, showed involution process, with mild neutrophilic and mononuclear infiltration. When compared to day 10 postpartum, the regenerative changes of epithelium and endometrial glandular activities were predominant on day 30 postpartum. In group II cows before treatment (at the time of animal selection), the uterine endometrium was intact. Multiple glandular acini and congestion were noticed. Uterine subendometrium showed few glandular acini lined with single layer of epithelial cells. After treatment (at AI), showed active proliferation of epithelial cells with intactness of endometrium. Uterus showed normal architecture of subendometrium with glandular acini. The intact endometrium with hyperplasia of endometrial glands was observed. The first service, second service and overall conception rates observed were 22.22, 33.33 and 55.55 and 37.50, 50.00 and 87.50 per cent in Group I and II, respectively. Hence it is concluded that increased conception rate after ovsynch treatment in postpartum cows positively correlated with the well healthy endometrium lining and glandular development.

\section{Introduction}

The uterine endometrial biopsy technique was more useful in evaluating the endometrial and ovarian status in post-partum cows. Microscopically, during postpartum period the uterine lining epithelium was found to be normal with pseudo-stratified columnar type. Sub-epithelial diffuse haemorrhages, cellular infiltration in uterine stroma and stromal oedema were observed. Uterine glands were found dilated and filled with desquamated material. Cytoplasmic vacuolation in glandular epithelium and oedema of uterine glands were observed (Morrow, 1980). Uterine biopsy was a valuable diagnostic tool in identifying morphological alterations in the uterine endometrium (Prasad and Krishna, 
2009). The endometrium of all mammals is richly endowed with glands that open on to the luminal surface. The endometrial glands secrete a variety of molecules, collectively termed as histotroph or uterine milk that is essential for maternal support of conceptus survival and growth in mammals (Gray et al., 2001). Pathak and Bansal (2012) observed that the endometrial glands were simple or branched tubular glands of which few were coiled distally. They were lined with simple columnar epithelium. These glands were more active during the follicular phase as compared to the luteal phase of the oestrous cycle. But the secretary activity was more pronounced during the luteal phase. Raja et al., (2012) reported that the histopathology of endometrium showed marked cellular changes of different degrees such as glandular hyperplasia, degenerative changes of the endometrium, cystic dilatation, mononuclear infiltration and perivascular fibrosis. Hence, the present investigation was formulated to study the effect of ovsynch treatment and CIDR on endometrial regeneration and conception rate in postpartum dairy cows.

\section{Materials and Methods}

An experiment was conducted in postpartum dairy cows which were selected from Large Animal Gynaecology unit of Teaching Veterinary Clinical Complex (TVCC), Veterinary College and Research Institute, Namakkal and from Veterinary Dispensaries, Tamil Nadu Co-operative Milk Producer Federation (TCMPF) Co-operative societies which are located in and around Namakkal district of Tamil Nadu for the study. Normally calved 16 healthy cows aged between $2^{\text {nd }}$ and $5^{\text {th }}$ lactations were selected immediately. Day of parturition was considered as day 0 of the experiment. On day 2 postpartum, cows of group I $(n=8)$ were treated with an intramuscular injection of $5 \mathrm{mg}$ methyl ergometrine maleate $\left(5 \mathrm{ml}\right.$, Utrasafe ${ }^{\circledR}$, Vet
Mankind, New Delhi, India). All the cows in group I were inserted with Controlled Internal Drug Release device (CIDR, EAZI - BREED, Pfizer Animal Health Ltd, India) (Plate 1) on day 45-55 postpartum intra-vaginally and left in situ for 9 days. All the cows had received an intramuscular injection of $25 \mathrm{mg}$ of $\mathrm{PGF}_{2} \alpha$ (5 ml, Lutalyse ${ }^{\circledR}$, Pfizer Animal Health Ltd, India) 24 hours before the withdrawal of CIDR and timed artificial insemination (TAI) was done at 48 and 72 hours after $\mathrm{PGF}_{2} \alpha$ injection. In group II cows were selected at 35-50 days postpartum. All the cows in group II were supplemented orally with TANUVAS mineral mixture daily @ 30-50 grams for 15 days. At the end of mineral mixture supplementation cow were treated with ovsynch protocol. The protocol included administration of $10 \mu \mathrm{g}$ of $\mathrm{GnRH}$ intramuscularly $(2.5 \mathrm{ml}$, Buserelin acetate, Ovulanta $^{\circledR}$, Vet Mankind, New Delhi) on the day of start of synchronization (day 0), $500 \mu \mathrm{g}$ of $\mathrm{PGF}_{2} \alpha$ intramuscularly ( $2 \mathrm{ml}$, Cloprostenol, Pragma ${ }^{\circledR}$, INTAS, Ahmedabad) seven days later (day 7), another $10 \mu \mathrm{g}$ of $\mathrm{GnRH}$ intramuscularly $48 \mathrm{~h}$ after $\mathrm{PGF}_{2} \alpha$ (day 9) and timed artificial insemination (TAI) was done at 16 to 18 hours after the second $\mathrm{GnRH}$ injection (day 10).

Endometrial biopsy was taken in group I cows on (i) day10 and (ii) day 30 postpartum and in group II cows (i) at the time of animal selection (before treatment) and (ii) at AI (after treatment), to study the histopathological changes of the uterine endometrium. Albuchin's uterine biopsy catheter (Plate 2a and 2b) was used to obtain endometrial biopsy samples as per the technique followed by Palanisamy (2012) with slight modifications. The closed, sterilized biopsy catheter was introduced into the uterus adopting aseptic technique. The biopsy catheter was advanced into one of the uterine horns of uterus and the catheter was opened. The uterine wall was pressed with the thumb 
against the opening of the catheter. The catheter was closed, rotated and retracted slowly. Slight pressure was applied against catheter to prevent haemorrhage before retracting the instrument. A piece of endometrium was released from the cutting edge of the catheter into a vial containing Bouin's fluid and stored for 24 hours and processed by routine paraffin technique and stained with haematoxyline and eosin as per technique described by Bancroft and Gamble (2008).

In both the groups fixed time artificial insemination done during the induced oestrus with good quality frozen thawed semen. Those animals which failed to conceive and returned to oestrus, were again inseminated during the subsequent oestrus. Conception rate was calculated as percentage of animals that conceived to AI at induced oestrus in both the groups. Pregnancy was confirmed by rectal palpation at 60 days post insemination.

\section{Results and Discussion}

The histopathology of uterine endometrium of group I cows is presented in Plate 3, the histopathology of uterine endometrium of group II cows before treatment (at the time of animal selection) is presented in Plate 4 and the histopathology of uterine endometrium of group II cows after treatment (at AI) is presented in Plate 5.

Uterine biopsies are routinely used for diagnosis of reproductive failures in human gynaecology and are thought to be the gold standard for endometrial evaluation in infertile women (Strowitzki et al., 2006). In this study in cows of the group I, on day 10 postpartum uterine lining epithelium was found to be normal with pseudostratified columnar type. Endometrium showed involution process with mild neutrophilic and mononuclear infiltration. The endometrial glandular activity was seen in few cases with increased vascular spaces. On day 30 postpartum there was an increased endometrial glandular activity with extensive lymphocytic infiltration.

These observations were in accordance with the findings of Prasad and Krishna (2009) in postpartum normally calved cows. In cows of the group II, the endometrial lining and glandular acini remained functional and unchanged before and after treatment without any degenerative changes or hyper plastic changes and it was in accordance with the findings of Singh et al., (1997) in buffaloes and Prasad and Krishna (2009) in cows. These endometrial involution and regenerative changes clearly reflected on the conception rate.

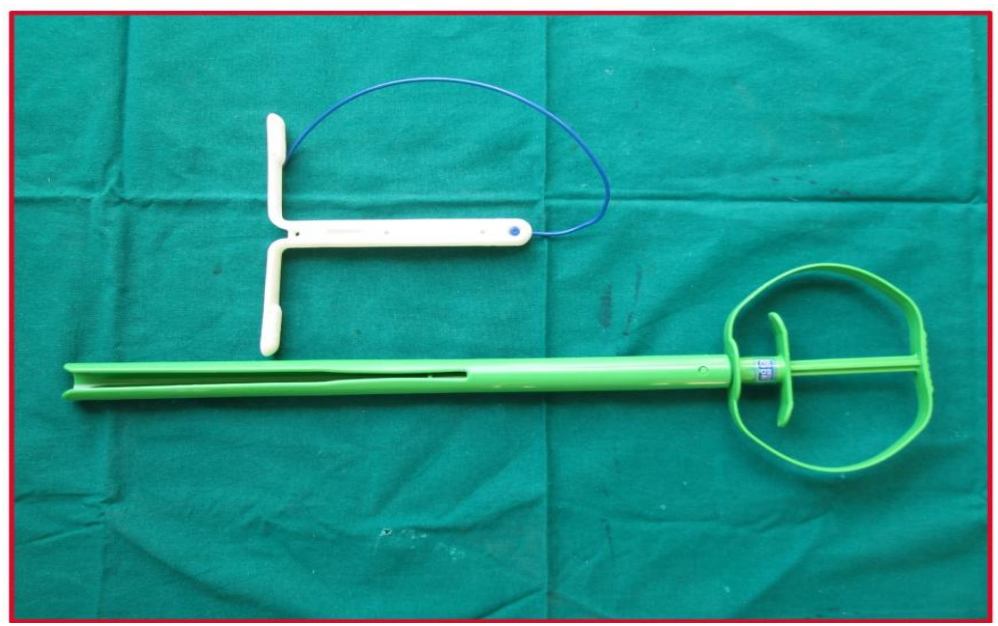

Plate.1 CIDR with Applicator 


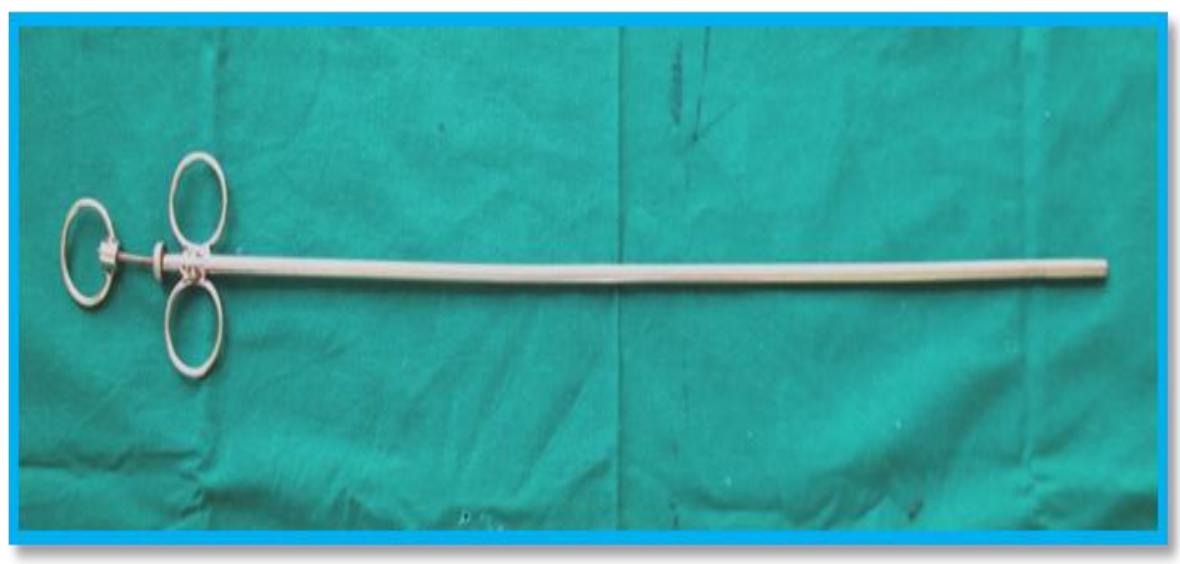

Plate.2a Albuchin's uterine biopsy catheter-with closed cut edge

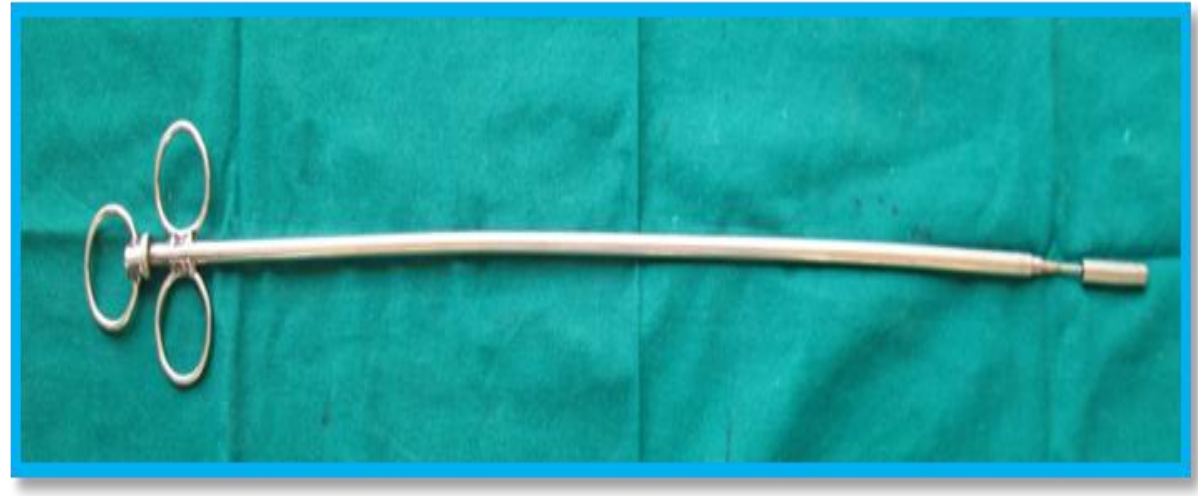

Plate.2b Albuchin's uterine biopsy catheter-with open tissue grasper

Plate.3 Histopathology of uterine endometrium in group I cows

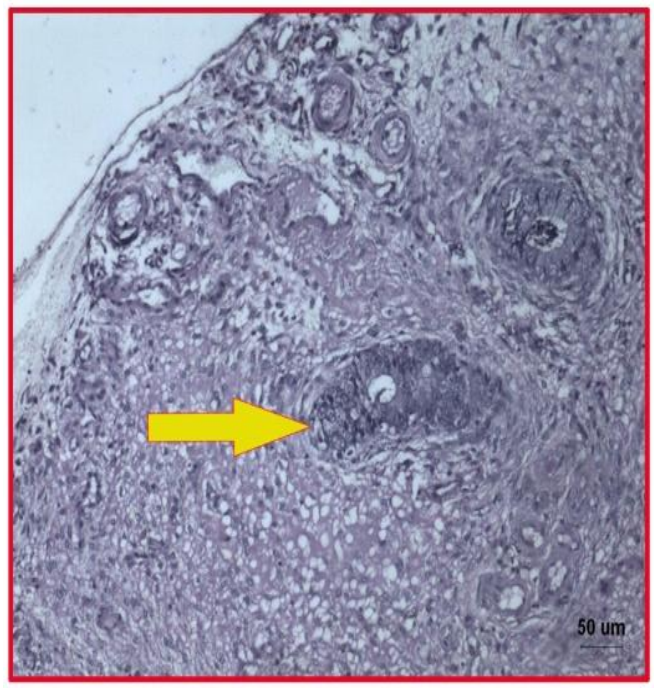

Day 10 postpartum

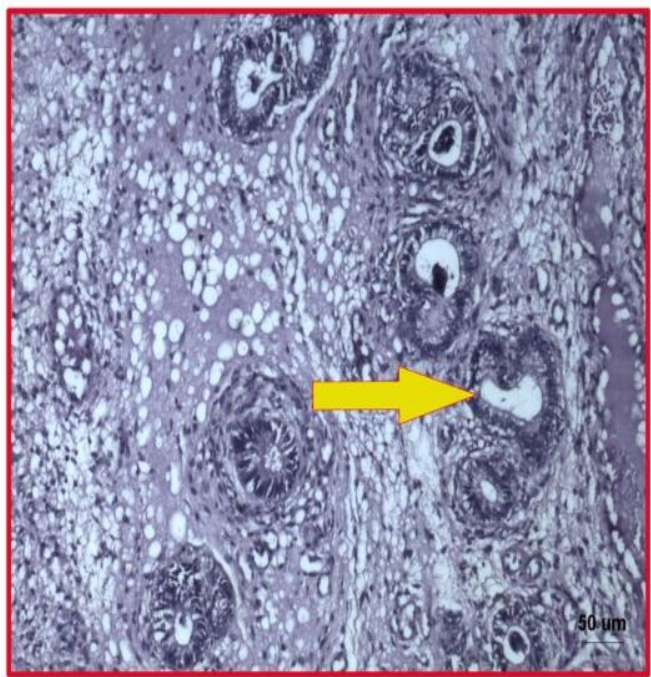

Day 30 postpartum

\section{Indicates endometrial gland and its secretory activity}

H\&E 400x 
Plate.4 Histopathology of uterine endometrium in group II cows - Before treatment (At the time of animal Selection)

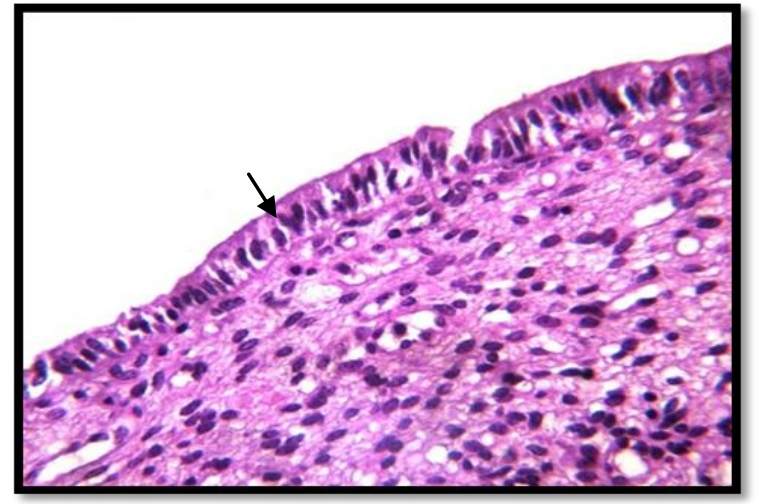

Normal uterus showing the intact endometrium.

H\&E 400x

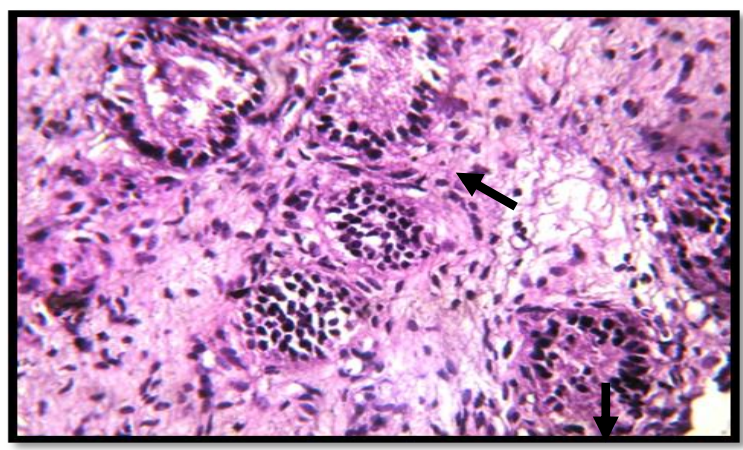

Uterine subendometrium showing few glandular acini lined with single layer of epithelial cells. $\mathbf{H} \& \mathbf{E} \mathbf{4 0 0 x}$

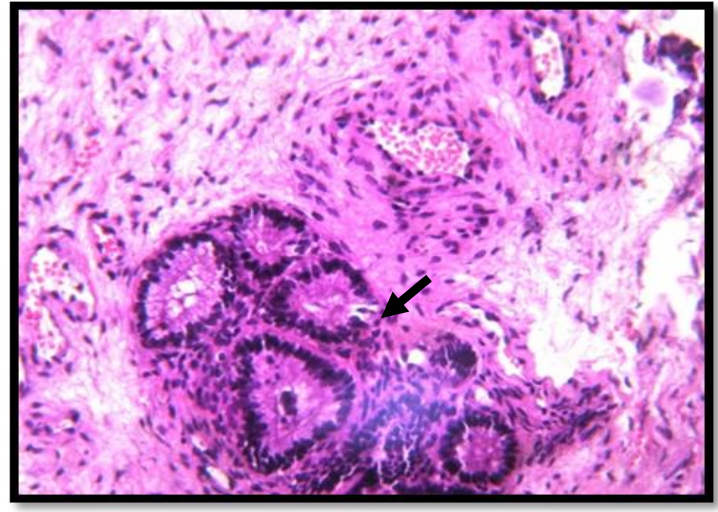

Normal uterus showing multiple glandular acini and congestion.

H\&E 200x

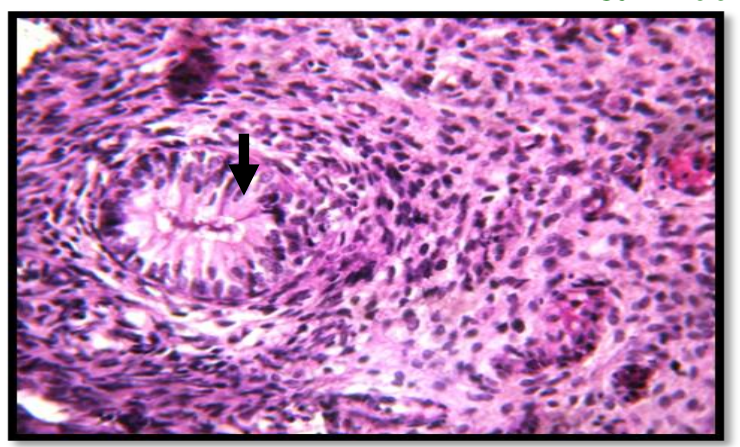

Uterus showing a solitary glandular acini lined by multi layers of epithelial cells.

H\&E 400x

Plate.5 Histopathology of uterine endometrium in group II cows - After treatment (At AI)

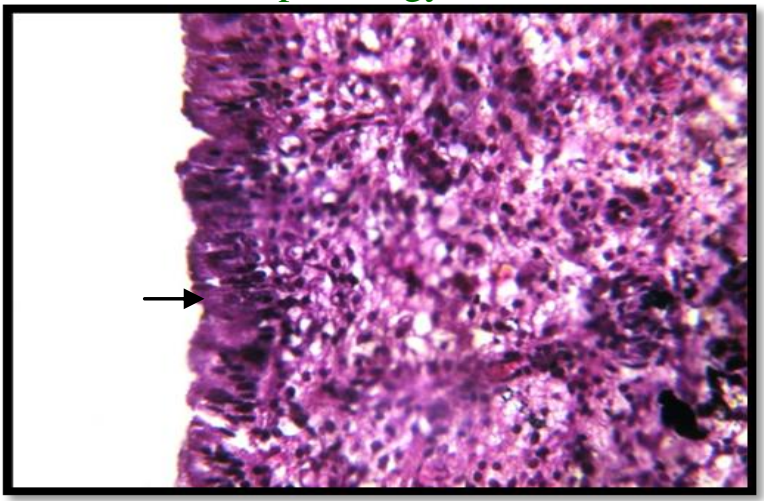

Uterus showing the proliferation of epithelial cells with intactness of endometrium.

H\&E 400x

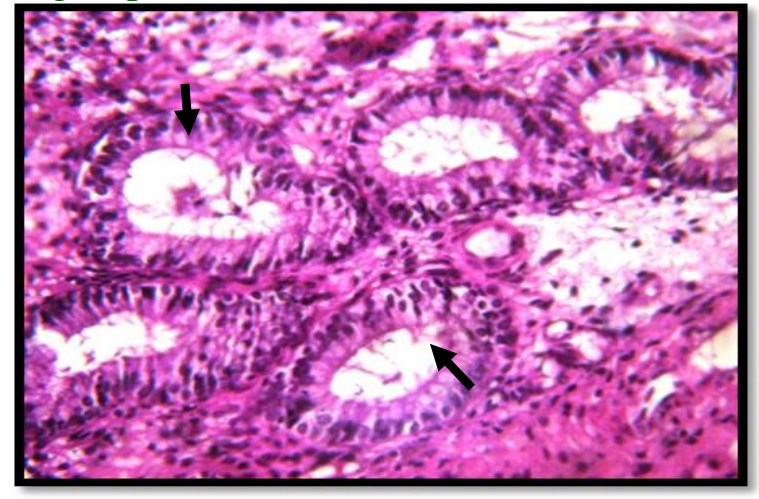

Uterus showing the active proliferation of epithelial cells lining the glandular acini. H\&E 400x 


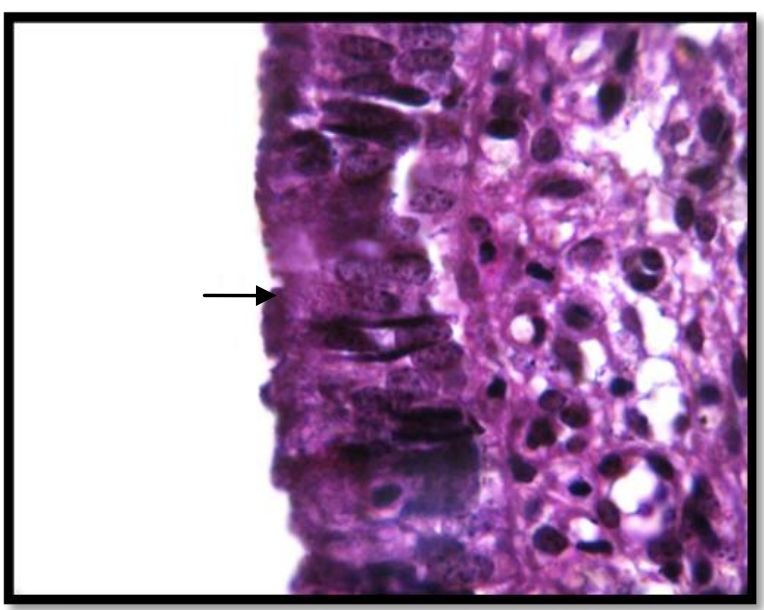

Uterus showing hyperplasia of epithelial cells lining endometrium.

H\&E 1000x

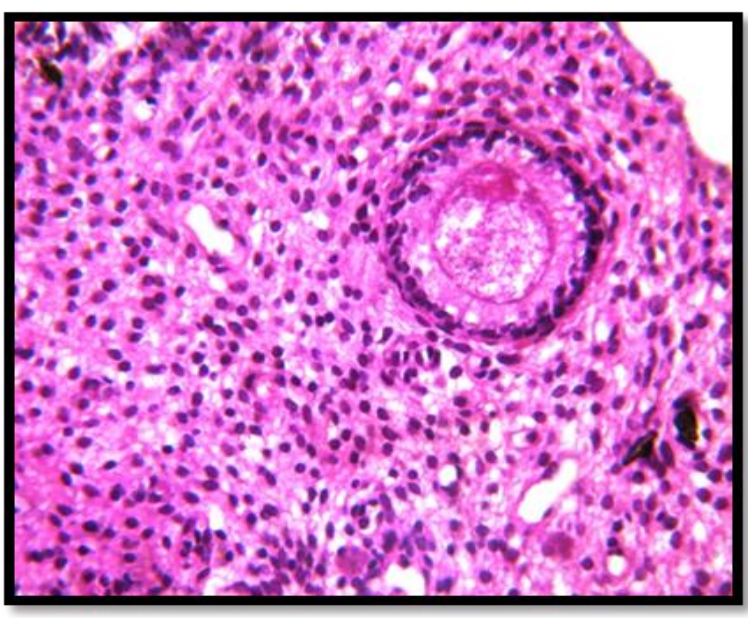

Uterus showing normal architecture of subendometrium with glandular acini.

H\&E 400x

The first service, second service and overall conception rates observed in this study were $22.22,33.33$ and 55.55 and $37.50,50.00$ and 87.50 per cent in group I and II, respectively. In group I cows treated with methyl ergometrine maleate on day 2 postpartum followed by oestrus induction with CIDR plus $\mathrm{PGF}_{2} \alpha$ on day 45-55 postpartum yielded 55.55 per cent overall conception rate. In this group the conception rate was better but it was lesser than group II. Ramoun et al., (2006) proved the enhancement of uterine involution due to the prolonged ecbolic effect of methyl ergometrine maleate in the uterus of buffaloes. Methyl ergometrine maleate produced firm, prolonged contraction of uterus that lasts for 3-4 hours (Roberts, 1986) by a gradual relaxation over a period of 1.5 hours (Drost, 1987). It indicated the uterine ecbolic drugs caused rapid uterine involution which leads to improvement in conception rates in group I cows.

Oestrus induction with ovsynch protocol at 50-65 days postpartum in group II cows yielded 87.50 per cent overall conception rates. It was in concurrence with the findings of Pursley et al., (1997). Greater conception rate achieved in the present study was due to

the commencement of ovsynch at appropriate stage of the oestrous cycle which would have induced preovulatory LH surge and ovulation as described by Moreira et al., (2000). The increasing trend in the conception rate from the first service to that of the second service could be attributed to the sensitization of the brain receptors by progesterone and good response to the ovarian estrogen from a large Graafian follicle of $>10 \mathrm{~mm}$ diameter followed by ovulation and formation of functional corpus luteum establishing pregnancy.

\section{References}

Bancroft, J.D. and Gamble, M. (2008). Theory and practice of histological techniques. $\quad 6^{\text {th }}$ ed., Churchill Livingston, Elsevier, Philadelphia.

Drost, M. (1987). Clinical uses of hormones. In 'Society for Theriogenology, Cow Manual, pp.73-80.

Gray, C.A., Taylor, K.M., Ramsey, W.S., Hill, J.R., Bazer, F.W., Bartol, F.F. and Spencer, T.E. (2001). Histomorphology of the endometrial gland of buffalo. Biol. Reprod., 64: 1608. 
Moreira, F., De la Sota, R.L., Diaz, T. and Thatcher, W.W. (2000). Effect of day of the estrous cycle at the initiation of a timed artificial insemination protocol on reproductive responses in dairy heifers. J. Anim. Sci., 78: 1568-1576.

Morrow, D.A. (1980). Current therapy in theriogenology. W.B. Saunders Company Philadelphia, London. pp. 7279.

Palanisamy, M. (2012). Efficacy of immunomodulators, lugol's iodine and prostaglandin $F_{2} \alpha$ in the treatment of post-partum endometritis in cows. Ph.D., thesis submitted to Tamil Nadu Veterinary and Animal Sciences University, Chennai.

Pathak, D. and Bansal, N. 2012. Histomorphology of the endometrial gland of Buffalo. Indian Vet. J., 89: 2528.

Prasad, B.C. and Krishna, K.M. (2009). Effect of RFM on histomorphology of uterine endometrium in cross bred cows. Tamil Nadu J. Vet. Anim. Sci., 5: 164-166.

Pursley, J.R., Kosorok, M.R. and Wiltbank, M.C. (1997). Reproductive management of lactating dairy cows using synchronization of ovulation. J. Dairy Sci., 80: 301-306.

Raja, S., Devanathan, T.G., Kulasekar, K., Pazhanivel, N. and Balachandran, C. (2012). White side test and endometrial biopsy for diagnosis of endometritis in repeat breeding cows. Indian J. Anim. Reprod., 33: 56-58.

Ramoun, A.A., Darweish, S.A., Abou, H.A. EI-Ghait and El-Fattouh, S.M. (2006). Effect of enhancement of uterine involution and earlier initiation of postpartum cyclicity on the reproductive performance of buffalo. Reprod. Fertil. Dev., 18: 545-550.

Roberts, S.J. (1986). Veterinary Obstetrics and Genital Diseases. $3^{\text {rd }}$ Edn.

Singh, J., Pierson, R.A. and Adams, G.P. (1997). Ultrasound images attributes of the bovine corpous luteum: structural and functional correlates. J. Reprod. Fertil., 109: 35-44.

Strowitzki, T., Germeyer, A., Popovici, R. and Wolff, M.V. (2006). The human endometrium as a fetility- determining factor. Hum. Reprod. Update, 12: 617630.

\section{How to cite this article:}

Velladurai, C., S. Alagar, M. Selvaraju and Ezakial Napolean, R. 2018. Uterine Endometrial Regeneration and Conception Rate Following Oestrus Induction with CIDR and Ovsynch Treatment in Postpartum Dairy Cows. Int.J.Curr.Microbiol.App.Sci. 7(03): 918-924. doi: https://doi.org/10.20546/ijcmas.2018.703.108 